Article

\title{
Association between Flow-Mediated Dilation and Skin Perfusion Pressure with Peripheral Artery Disease in Hemodialysis Patients
}

\author{
Chih-Hsuan Wung ${ }^{1}{ }^{(0)}$, Yu-Hsiu Wang ${ }^{2}$, Yuang-Chi Lee ${ }^{2}$, Chieh-Wei Chang ${ }^{2}$, Pei-Yu Wu ${ }^{3,4}$, Jiun-Chi Huang ${ }^{3,4,5}{ }^{(0}$, \\ Yi-Chun Tsai ${ }^{4,5} \mathbb{C}^{-}$, Szu-Chia Chen ${ }^{3,4,5}, * \mathbb{D}$, Jer-Ming Chang ${ }^{4,5} \mathbb{D}^{-}$and Shang-Jyh Hwang ${ }^{4,5, *}$ \\ 1 Department of Post Baccalaureate Medicine, Kaohsiung Medical University, Kaohsiung 807, Taiwan; \\ knash031130@hotmail.com.tw \\ 2 Department of Nursing, Kaohsiung Municipal Siaogang Hospital, Kaohsiung Medical University, \\ Kaohsiung 812, Taiwan; eightshiou@gmail.com (Y.-H.W.); yaungchi2021@gmail.com (Y.-C.L.); \\ stacy97761014@gmail.com (C.-W.C.) \\ 3 Division of Nephrology, Department of Internal Medicine, Kaohsiung Medical University Hospital, \\ Kaohsiung Medical University, Kaohsiung 807, Taiwan; wpuw17@gmail.com (P.-Y.W.); \\ karajan77@gmail.com (J.-C.H.) \\ 4 Department of Internal Medicine, Kaohsiung Municipal Siaogang Hospital, Kaohsiung Medical University, \\ Kaohsiung 812, Taiwan; lidam65@yahoo.com.tw (Y.-C.T.); jemich@kmu.edu.tw (J.-M.C.) \\ 5 Faculty of Medicine, College of Medicine, Kaohsiung Medical University, Kaohsiung 807, Taiwan \\ * Correspondence: scarchenone@yahoo.com.tw (S.-C.C.); sjhwang@kmu.edu.tw (S.-J.H.); \\ Tel.: +886-7-8036783 (ext. 3440) (S.-C.C.); +886-7-3121101 (ext. 7351) (S.-J.H.); Fax: +886-7-8063346 (S.-C.C.)
}

Citation: Wung, C.-H.; Wang, Y.-H.; Lee, Y.-C.; Chang, C.-W.; Wu, P.-Y.; Huang, J.-C.; Tsai, Y.-C.; Chen, S.-C.; Chang, J.-M.; Hwang, S.-J.

Association between Flow-Mediated Dilation and Skin Perfusion Pressure with Peripheral Artery Disease in Hemodialysis Patients. J. Pers. Med. 2021, 11, 1251. https://doi.org/ 10.3390/jpm11121251

Academic Editors: Elizabeth Vafiadaki and Andreas P. Kalogeropoulos

Received: 27 October 2021

Accepted: 24 November 2021

Published: 25 November 2021

Publisher's Note: MDPI stays neutral with regard to jurisdictional claims in published maps and institutional affiliations.

Copyright: () 2021 by the authors. Licensee MDPI, Basel, Switzerland. This article is an open access article distributed under the terms and conditions of the Creative Commons Attribution (CC BY) license (https:// creativecommons.org/licenses/by/ $4.0 /)$

\begin{abstract}
Flow-mediated dilation (FMD) is used to noninvasively assess the health of blood vessels and it has been shown to have a similar predictive ability for cardiovascular disease to traditional risk factors. Skin perfusion pressure (SPP) refers to the blood pressure required to restore capillary or microcirculatory flow after controlled occlusion and the return of flow. SPP has been shown to be an important measurement when making clinical decisions for patients with limb ischemia and to be a predictor of the likelihood of wound healing. Peripheral artery disease is common in hemodialysis (HD) patients. However, little is known about the association between FMD or SPP and peripheral artery disease. The aim of this study was to evaluate the association between FMD and SPP with brachial-ankle pulse wave velocity (baPWV) and ankle-brachial index (ABI) in HD patients in Taiwan, an area with a high rate of ESRD. This study was conducted at a regional hospital in southern Taiwan. ABI and baPWV values were measured using an ABI automated device. FMD and SPP were measured using ultrasound and a microvasculature blood flow monitor, respectively. Eighty patients were enrolled in this study. Compared to the patients with an $\mathrm{ABI} \geq 0.95$, those with an $\mathrm{ABI}<0.95$ had lower SPP of the feet (dorsal and plantar portions, both $p<0.001$ ). After multivariable adjustments, low triglycerides $(p=0.033)$ and high calcium-phosphate product $(p=0.018)$ were significantly associated with low FMD. Further, low ABI $(p=0.001)$ and low baPWV $(p=0.036)$ were significantly associated with low SPP of dorsal portions. Old age $(p=0.005)$, low high-density lipoprotein cholesterol $(p=0.016)$, and low ABI $(p=0.002)$ were significantly associated with low SPP of plantar portions. This study demonstrated an association between FMD and SPP with peripheral artery disease in HD patients. Patients with low ABI and baPWV had a high risk of low SPP of the feet. However, there was no significant correlation between FMD and ABI or baPWV.
\end{abstract}

Keywords: flow-mediated dilation; skin perfusion pressure; ankle-brachial index; brachial-ankle pulse wave velocity; hemodialysis

\section{Introduction}

Cardiovascular (CV) morbidity and mortality rates in hemodialysis (HD) patients are high due to endothelial dysfunction caused by uremic toxins and oxidative stress [1] 
Endothelial dysfunction can lead to peripheral artery disease (PAD) [2], which is a common complication in HD patients with rates ranging from $17 \%$ to $48 \%[3,4]$. The serious complications of PAD are detrimental to the outcomes of HD patients [5], because PAD has been associated with coronary artery disease, congestive heart failure and foot lesions in many cohort studies [6].

Flow-mediated dilation (FMD) is used to noninvasively assess the health of blood vessels (endothelial dysfunction) and is measured using high-resolution ultrasound [7]. It is expressed as percentage change of the arterial diameter from the baseline diameter [8]. FMD has been used in both clinical research and clinical practice [9], and it has been shown to be strongly predictive of future CV events in patients with diabetes mellitus (DM) [10]. Moreover, two previous studies have demonstrated impaired FMD in patients with endstage renal disease [11,12]. Skin perfusion pressure (SPP) refers to the blood pressure (BP) required to restore capillary or microcirculatory flow after controlled occlusion and the return of flow [13]. It has been shown to be an important measurement when making clinical decisions for patients with limb ischemia and to be a predictor of the likelihood of wound healing [14]. The advantages of SPP include its non-invasiveness, high reproducibility and independence from the impact of calcification [15].

The ankle-brachial index (ABI) and brachial-ankle pulse wave velocity (baPWV) have been shown to be good markers of PAD and vascular damage and they have both been used to identify PAD in HD patients [16-18]. However, little is known about the association between FMD and SPP with PAD. Therefore, the aim of this study was to evaluate the association between FMD, SPP, ABI, and baPWV in Taiwanese HD patients.

\section{Subjects and Methods}

\subsection{Study Patients and Design}

A study was conducted in the dialysis clinic of a regional hospital in Taiwan in April 2021. The inclusion criteria were patients who had undergone HD for at least three months at age older than 18 years $(n=120)$. The exclusion criteria were patients who: $(1)$ refused to undergo FMD, SPP, ABI, or baPWV examinations $(n=27)$; (2) had unilateral or bilateral below the knee amputations $(n=3)$; (3) had bilateral forearm blood access $(n=5)$; and (4) had been hospitalized or received antibiotic treatment in the last four weeks $(n=5)$ (Figure 1). The remaining 80 patients ( 47 males and 33 females; mean age $63.8 \pm 11.1$ years) were included. Each HD session lasted for 3.5-4.0 h, and each patient underwent three sessions per week. The blood flow rate was set at 250-300 $\mathrm{mL} / \mathrm{min}$, with a dialysate flow rate of $500 \mathrm{~mL} / \mathrm{min}$. The values of FMD, SPP, ABI and baPWV were measured midway through an HD session.

All of the patients provided written informed consent to participate in this study, which was approved by the Institutional Review Board of Kaohsiung Medical University Hospital (KMUHIRB-E(II)-20200315). The methods were carried out in accordance with the approved guidelines.

\subsection{Assessment of FMD}

All studies were performed in a quiet, dark, air-conditioned room (constant temperature of $22-25^{\circ} \mathrm{C}$ ). The subjects remained supine throughout the study. The vascular response to reactive hyperemia in the brachial artery was assessed for ultrasound assessment of endothelium-dependent FMD [19]. A high-resolution linear artery transducer was coupled to computer-assisted analysis software (UNEXEF18G, UNEX Co, Nagoya, Japan) that used an automated edge detection system for measurement of brachial artery diameter. A blood pressure cuff was placed around the side of the forearm without vascular access. The brachial artery was scanned longitudinally 5 to $10 \mathrm{~cm}$ above the elbow. When the clearest B-mode image of the anterior and posterior intimal interfaces between the lumen and vessel wall was obtained, the transducer was held at the same point throughout the scan by a special probe holder (UNEX Co) to ensure the consistency of the image. Depth and gain settings were set to optimize the images of the arterial lumen wall interface. 
When the tracking gate was placed on the intima, the artery diameter was automatically tracked and the waveform of diameter changes over the cardiac cycle was displayed in real time with the use of the FMD mode of the tracking system. This allowed the ultrasound images to be optimized at the start of the scan and the transducer position to be adjusted immediately for optimal tracking performance throughout the scan. Pulsed Doppler flow was assessed at baseline and during peak hyperemic flow, which was confirmed to occur within $15 \mathrm{~s}$ after cuff deflation. Blood flow velocity was calculated from the color Doppler data and was displayed as a waveform in real time. The baseline longitudinal image of the artery was acquired for $30 \mathrm{~s}$, and then the blood pressure cuff was inflated to $50 \mathrm{~mm}$ $\mathrm{Hg}$ above systolic pressure for $5 \mathrm{~min}$. The longitudinal image of the artery was recorded continuously until 5 min after cuff deflation. Pulsed Doppler velocity signals were obtained for $20 \mathrm{~s}$ at baseline and for $10 \mathrm{~s}$ immediately after cuff deflation. Changes in brachial artery diameter were immediately expressed as percent change relative to the vessel diameter before cuff inflation. FMD was automatically calculated as the percent change in peak vessel diameter from the baseline value. The measurement \%FMD (peak diameter-baseline diameter/baseline diameter) was used for analysis. Blood flow volume was calculated by multiplying the Doppler flow velocity (corrected for the angle) by heart rate and vessel cross-sectional area $(\pi \mathrm{r} 2)$. Reactive hyperemia was calculated as the maximum percent increase in flow after cuff deflation compared with baseline flow. The FMD measurements were done once in each patient.

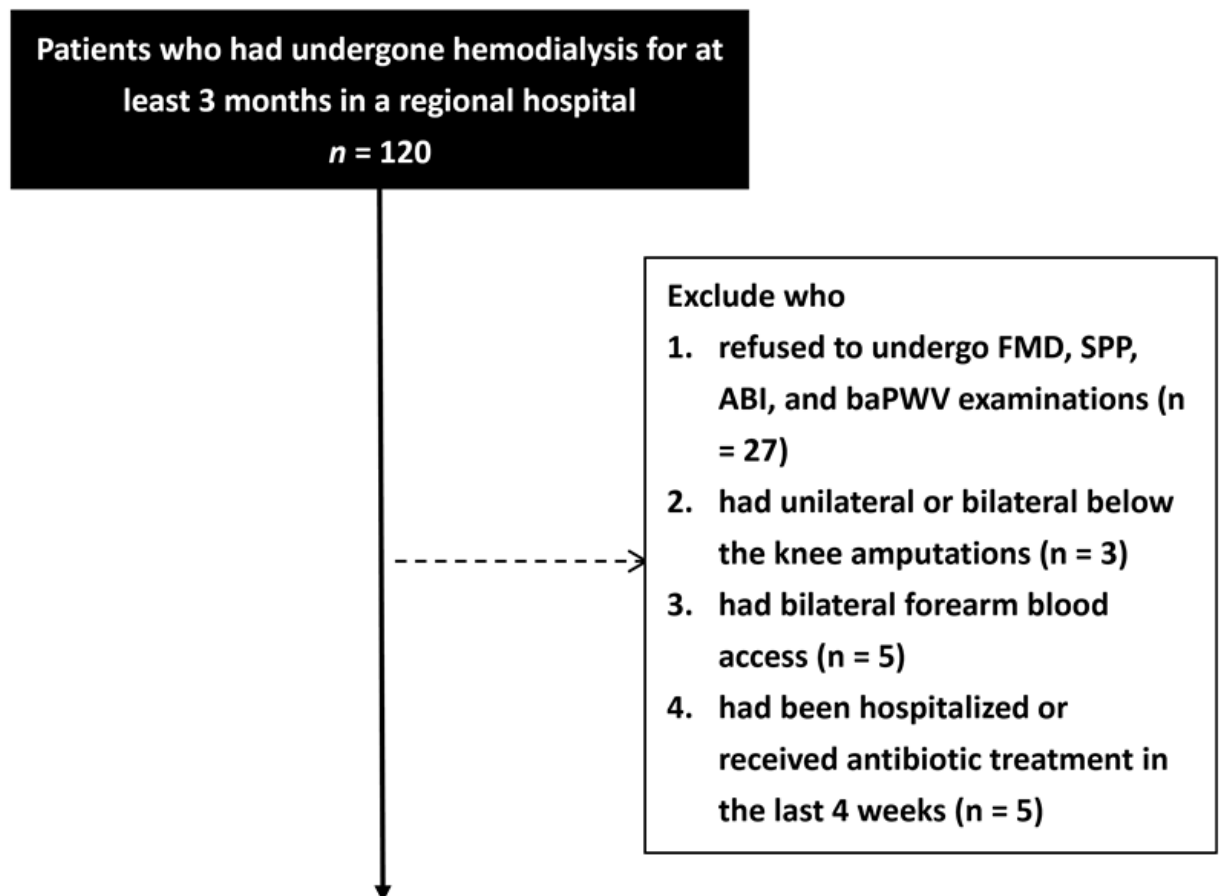

Study patients received FMD, SPP, ABI, and baPWV examinations in the present study $n=80$

Figure 1. Flowchart of study population.

\subsection{Assessment of SPP of the Feet}

SPP measurements of the plantar and dorsal portions of the feet were obtained in each patient using a microvasculature blood flow monitor (Nahri MV monitor; Nexis, Tokyo, Japan). Suprasystolic compression was performed at the measurement point to stop blood flow and then the cuff was slowly deflated until the return of blood flow was detected by an optical sensor utilizing laser Doppler technology. Examinations were usually performed 
in the afternoon after the patients had been allowed to rest for around $30 \mathrm{~min}$. If the patient had an open wound at the measurement site, SPP was measured as close to the wound as possible. Both feet of each patient were measured twice, and the four times were averaged.

\subsection{Assessment of $A B I$ and baPWV}

The values of ABI and baPWV were measured using an ABI automated device (VP1000; Colin Co. Ltd., Komaki, Japan), which automatically and simultaneously measures blood pressures in both arms and ankles using an oscillometric method [20]. Monitoring and occlusion cuffs were attached firmly around both sides of the lower extremities and the upper arm (without vascular access) of the patient while they were in the supine position. ABI was calculated as the lower value of ankle systolic BP divided by that in the arm. ABI was measured once in each patient. The lower of bilateral ABI values was used in the analysis. Patients with PAD were defined as those with ABI $<0.95$ [21].

$\mathrm{BaPWV}$ was measured using an automated oscillometric device that recorded pulse waves in the brachial and posterior tibial arteries [22-24]. The transmission time $(\Delta \mathrm{Tba})$ was calculated as the time between the initial increases in brachial and ankle waveforms. The brachial to ankle transmission distance was then calculated based on the height of the patient. The distances from the suprasternal notch to the brachium ( $\mathrm{Lb}$ ) and ankle $(\mathrm{La})$ were calculated as: $\mathrm{Lb}=0.2195 \times$ height of the patient $($ in $\mathrm{cm})-2.0734$; and $\mathrm{La}=0.8129 \times$ height of the patient (in $\mathrm{cm})+12.328$. BaPWV was then calculated as $(\mathrm{La}-\mathrm{Lb}) / \triangle \mathrm{Tb}$. The higher of the bilateral baPWV values was used in the analysis. BaPWV was measured once in each patient.

\subsection{Collection of Demographic, Medical, and Laboratory Data}

The medical records of each patient were used to obtain data on age, sex and a history of diabetes, hypertension, coronary artery disease, and cerebrovascular disease. Blood samples were obtained after a $12 \mathrm{~h}$ fast within 1 month of enrollment and analyzed using an autoanalyzer (COBAS Integra 400, Roche Diagnostics GmbH, D-68298 Mannheim, Germany). All of the participants also underwent physical examinations, during which body weight and height were recorded. Body mass index (BMI) was calculated as $\mathrm{kg} / \mathrm{m}^{2}$.

\subsection{Statistical Analysis}

Descriptive statistics are presented as number (percentage) or mean \pm standard deviation. Between-group comparisons were performed using the independent $t$ test for continuous variables and chi-square test for categorical variables. Multivariable stepwise linear regression analysis was used to evaluate the association between ABI and baPWV with FMD and SPP. A $p$ value $<0.05$ was considered to be statistically significant. All statistical analyses were performed using SPSS version 22.0 for Windows (SPSS Inc., Chicago, IL, USA).

\section{Results}

3.1. Comparison of the Clinical Characteristics among the Patients with an $A B I<0.95$ or $\geq 0.95$

The characteristics of the patients with an ABI $<0.95$ or $\geq 0.95$ are shown in Table 1 . Compared to the patients with an $\mathrm{ABI} \geq 0.95$, those with an $\mathrm{ABI}<0.95$ had higher prevalence rates of diabetes and cerebrovascular disease, lower diastolic BP, higher BMI, lower high-density lipoprotein (HDL)-cholesterol, and lower SPP of the feet (dorsal and plantar portions, both $p<0.001$ ). 
Table 1. Comparison of clinical characteristics among HD patients with $\mathrm{ABI}<0.95$ or $\geq 0.95$.

\begin{tabular}{|c|c|c|c|}
\hline Characteristics & $\begin{array}{c}\mathrm{ABI} \geq 0.95 \\
(n=51)\end{array}$ & $\begin{array}{c}\mathrm{ABI}<0.95 \\
(n=29)\end{array}$ & $p$ \\
\hline Age (year) & $62.6 \pm 12.3$ & $65.6 \pm 8.2$ & 0.246 \\
\hline Male number (\%) & $30(58.8)$ & $17(58.6)$ & 0.986 \\
\hline DM number (\%) & $22(43.1)$ & $21(72.4)$ & 0.012 \\
\hline Hypertension number (\%) & $36(70.6)$ & $23(79.3)$ & 0.394 \\
\hline Coronary artery disease number (\%) & $11(21.6)$ & $11(37.9)$ & 0.115 \\
\hline Cerebrovascular disease number $(\%)$ & $5(9.8)$ & $9(31.0)$ & 0.013 \\
\hline Systolic blood pressure (mmHg) & $138.5 \pm 22.1$ & $128.7 \pm 26.8$ & 0.083 \\
\hline Diastolic blood pressure (mmHg) & $77.6 \pm 14.2$ & $70.8 \pm 9.2$ & 0.022 \\
\hline Pulse pressure $(\mathrm{mmHg})$ & $60.9 \pm 12.3$ & $58.0 \pm 20.0$ & 0.477 \\
\hline BMI $\left(\mathrm{kg} / \mathrm{m}^{2}\right)$ & $23.4 \pm 4.1$ & $25.5 \pm 3.7$ & 0.027 \\
\hline \multicolumn{4}{|l|}{ Laboratory parameters } \\
\hline Fasting glucose (mg/dL) & $148.1 \pm 58.7$ & $135.2 \pm 51.7$ & 0.459 \\
\hline Albumin (g/dL) & $3.9 \pm 0.2$ & $3.9 \pm 0.2$ & 0.859 \\
\hline Hemoglobin (g/dL) & $10.8 \pm 0.8$ & $11.1 \pm 1.0$ & 0.151 \\
\hline Triglyceride (mg/dL) & $128.8 \pm 95.8$ & $129.6 \pm 69.5$ & 0.971 \\
\hline Total cholesterol (mg/dL) & $157.4 \pm 30.3$ & $153.1 \pm 40.8$ & 0.600 \\
\hline HDL-cholesterol (mg/dL) & $44.9 \pm 16.1$ & $37.5 \pm 8.8$ & 0.010 \\
\hline LDL-cholesterol (mg/dL) & $77.3 \pm 26.2$ & $81.6 \pm 31.8$ & 0.524 \\
\hline Calcium-phosphate product $\left(\mathrm{mg}^{2} / \mathrm{dL}^{2}\right)$ & $42.2 \pm 10.1$ & $45.0 \pm 11.9$ & 0.284 \\
\hline \multicolumn{4}{|l|}{ Exams } \\
\hline $\mathrm{ABI}$ & $1.1 \pm 0.1$ & $0.8 \pm 0.1$ & $<0.001$ \\
\hline $\mathrm{baPWV}(\mathrm{cm} / \mathrm{s})$ & $1951.8 \pm 395.8$ & $1828.3 \pm 557.9$ & 0.253 \\
\hline $\operatorname{FMD}(\%)$ & $3.6 \pm 2.5$ & $3.4 \pm 2.0$ & 0.711 \\
\hline SPP of dorsal portion of foot $(\mathrm{mmHg})$ & $103.4 \pm 20.9$ & $82.0 \pm 23.9$ & $<0.001$ \\
\hline SPP of plantar portion of foot (mmHg) & $88.2 \pm 21.7$ & $64.0 \pm 21.6$ & $<0.001$ \\
\hline
\end{tabular}

$\overline{\text { Abbreviations. HD, hemodialysis; ABI, ankle-brachial index; baPWV, brachial-ankle pulse wave velocity; DM, }}$ diabetes mellitus; BMI, body mass index; HDL, high-density lipoprotein; LDL, low-density lipoprotein; FMD, flow-mediated dilation; SPP, skin perfusion pressure.

\subsection{Risk Factors for FMD}

The factors associated with FMD in multivariable stepwise linear regression analysis after adjusting for age, sex, DM, hypertension, coronary artery disease, cerebrovascular disease, BMI, fasting glucose, albumin, hemoglobin, triglycerides, total cholesterol, HDLcholesterol, low-density lipoprotein cholesterol, calcium-phosphate product, ABI and baPWV are shown in Table 2. Low triglycerides (per $1 \mathrm{mg} / \mathrm{dL}$; unstandardized coefficient $\beta$, $0.007 ; 95 \%$ confidence interval [CI], 0.001 to $0.013 ; p=0.033$ ) and high calcium-phosphate product (per $1 \mathrm{mg}^{2} / \mathrm{dL}^{2}$; unstandardized coefficient $\beta,-0.084 ; 95 \% \mathrm{CI},-0.152$ to -0.015 ; $p=0.018$ ) were significantly associated with low FMD. However, ABI and baPVW did not achieve significance.

Table 2. Determinants for FMD using multivariable stepwise linear regression analysis.

\begin{tabular}{ccc}
\hline \multirow{2}{*}{ Characteristics } & \multicolumn{2}{c}{ Multivariable (Stepwise) } \\
\cline { 2 - 3 } & Unstandardized Coefficient $\boldsymbol{\beta}$ (95\% CI) & $p$ \\
\hline Triglyceride (per 1 $\mathrm{mg} / \mathrm{dL})$ & $0.007(0.001,0.013)$ & 0.033 \\
calcium-phosphate product $\left(\right.$ per $\left.1 \mathrm{mg}^{2} / \mathrm{dL}^{2}\right)$ & $-0.084(-0.152,-0.015)$ & 0.018 \\
\hline
\end{tabular}

Values expressed as unstandardized coefficient $\beta$ and $95 \%$ confidence interval (CI). Abbreviations are the same as in Table 1.

Multivariable adjusted for age, sex, DM, hypertension, coronary artery disease, cerebrovascular disease, BMI, fasting glucose, albumin, hemoglobin, triglyceride, total cholesterol, HDL-cholesterol, LDL-cholesterol, calcium-phosphate product, ABI and baPWV.

We further performed a subgroup analysis after the exclusion of two patients with $\mathrm{ABI}>1.3$, and found similar results. Low triglycerides and high calcium-phosphate product were significantly associated with low FMD. 


\subsection{Risk Factors for SPP of Dorsal Portions}

The factors associated with SPP of dorsal portions are shown in Table 3. After multivariable adjustments, low ABI (per 0.1; unstandardized coefficient $\beta, 6.561 ; 95 \%$ CI, 2.719 to $10.402 ; p=0.001$ ) and low baPWV (per $100 \mathrm{~cm} / \mathrm{s}$; unstandardized coefficient $\beta$, 1.442 ; $95 \%$ CI, 0.101 to $2.783 ; p=0.036$ ) were significantly associated with low SPP of dorsal portions.

Table 3. Determinants for SPP of dorsal portion of foot using multivariable stepwise linear regression analysis.

\begin{tabular}{ccc}
\hline \multirow{2}{*}{ Characteristics } & \multicolumn{2}{c}{ Multivariable (Stepwise) } \\
\cline { 2 - 3 } & Unstandardized Coefficient $\boldsymbol{\beta}$ (95\% CI) & $p$ \\
\hline ABI (per 0.1) & $6.561(2.719,10.402)$ & 0.001 \\
baPWV (per $100 \mathrm{~cm} / \mathrm{s})$ & $1.442(0.101,2.783)$ & 0.036 \\
\hline
\end{tabular}

Values expressed as unstandardized coefficient $\beta$ and $95 \%$ confidence interval (CI). Abbreviations are the same as in Table 1.

Multivariable was adjusted for age, sex, DM, hypertension, coronary artery disease, cerebrovascular disease, BMI, fasting glucose, albumin, hemoglobin, triglyceride, total cholesterol, HDL-cholesterol, LDL-cholesterol, calcium-phosphate product, ABI and baPWV.

We further performed a subgroup analysis after the exclusion of two patients with $\mathrm{ABI}>1.3$ and found similar results. Low $\mathrm{ABI}$ and low baPWV were significantly associated with low SPP of dorsal portions.

\subsection{Risk Factors for SPP of Plantar Portions}

The factors associated with SPP of plantar portions are shown in Table 4. After multivariable adjustments, old age (per 1 year; unstandardized coefficient $\beta,-0.958$; $95 \% \mathrm{CI},-1.612$ to $-0.304 ; p=0.005$ ), low HDL-cholesterol (per $1 \mathrm{mg} / \mathrm{dL}$; unstandardized coefficient $\beta, 0.722 ; 95 \% \mathrm{CI}, 0.144$ to $1.300 ; p=0.016$ ), and low ABI (per 0.1; unstandardized coefficient $\beta, 5.289 ; 95 \% \mathrm{CI}, 2.091$ to $8.486 ; p=0.002$ ) were significantly associated with low SPP of plantar portions.

Table 4. Determinants for SPP of plantar portion of foot using multivariable stepwise linear regression analysis.

\begin{tabular}{ccc}
\hline \multirow{2}{*}{ Characteristics } & \multicolumn{2}{c}{ Multivariable (Stepwise) } \\
\cline { 2 - 3 } & Unstandardized Coefficient $\boldsymbol{\beta} \mathbf{~ ( 9 5 \% ~ C I ) ~}$ & $p$ \\
\hline Age (per 1 year) & $-0.958(-1.612,-0.304)$ & 0.005 \\
HDL-cholesterol (per 1 mg/dL) & $0.722(0.144,1.300)$ & 0.016 \\
ABI (per 0.1) & $5.289(2.091,8.486)$ & 0.002 \\
\hline
\end{tabular}

Values expressed as unstandardized coefficient $\beta$ and $95 \%$ confidence interval (CI). Abbreviations are the same as in Table 1.

Multivariable was adjusted for age, sex, DM, hypertension, coronary artery disease, cerebrovascular disease, BMI, fasting glucose, albumin, hemoglobin, triglyceride, total cholesterol, HDL-cholesterol, LDL-cholesterol, calcium-phosphate product, ABI and baPWV.

We further performed a subgroup analysis after the exclusion of two patients with $\mathrm{ABI}>1.3$ and found the similar results. Old age, low HDL-cholesterol, and low ABI were significantly associated with low SPP of plantar portions.

\section{Discussion}

In this study, we evaluated the association between FMD and SPP with ABI and baPWV in $80 \mathrm{HD}$ patients. We found that a low ABI and low baPWV were associated with low SPP of dorsal portions and that a low ABI was associated with low SPP of plantar portions. However, there was no significant correlation between FMD with ABI and baPWV. 
The first finding of our study is that there was no correlation between FMD and ABI or baPWV. Gupta et al. reported a positive correlation between FMD and ABI in young males post myocardial infarction in India [25]. However, Vigna et al. found no significant correlation between ABI and FMD in a dyslipidemic population [26], and Kaczmarczyk et al. reported no correlation between ABI, toe-brachial index and FMD among patients with PAD [27]. Taken together with our finding of no correlation between FMD and ABI among HD patients, it appears that the relationship between FMD and ABI varies among different populations. A possible explanation of no correlation between FMD and ABI or baPWV is that FMD is predominantly affected by nitrogen oxide (NO) [8], whereas PAD develops through lower limb artery atherosclerosis, an imbalance in lipid metabolism and chronic inflammation. On the other hand, Tomiyama et al. reported a non-significant correlation between FMD and baPWV among hypertensive patients [28], and Nakaruma et al. also reported no significant difference between FMD and baPWV among patients with coronary artery disease [29]. We also found no correlation between FMD and baPWV among HD patients. A reasonable explanation is that FMD mainly reflects endothelial dysfunction [30], whereas baPWV reflects arterial stiffening through both structural and functional changes including endothelial dysfunction, elevated smooth muscle tone and medial hypertrophy related to the development of atherosclerosis [31]. Vascular endothelial dysfunction is the first step of atherosclerosis, [32], and the progression of atherosclerosis may partly explain why there was no significant correlation between FMD with ABI and baPWV in this study.

The second finding of this study is that low ABI was associated with low SPP of both dorsal and plantar portions of the feet and that low baPWV was associated with low SPP of dorsal portions. Davis et al. and Ishioka et al. also found that SPP was positively associated with ABI among HD patients $[33,34]$ and Shimazaki et al. found that SPP decreased significantly in HD patients with lower ABI compared to those with normal ABI [35]. SPP reflects blood flow in the microcirculatory system, hence it can be used to assist in the assessment of PAD [36]. Marginal ischemia with limited wound healing in PAD patients has been associated with a low SPP value [14]. In this study, we also found that low baPWV was associated with low SPP of dorsal portions. A possible explanation is vessel occlusion. Obvious stenosis or occlusion of blood vessels would affect the velocity of pulse waves, leading to lower baPWV values [37]. At the same time, occlusion would affect the restoration of microcirculatory or capillary flow, leading to a lower SPP value [13] However, further studies are needed to elucidate this hypothesis.

The third finding of this study is that a low triglyceride level was significantly associated with low FMD. Samsamshariat et al. found no association between FMD and triglycerides among both subjects with and without metabolic syndrome [38]. In addition, Fukumoto et al. found that FMD was inversely correlated with triglyceride level among patients with mild hypertriglyceridemia [39], and Kajikawa et al. demonstrated that higher serum triglyceride levels were associated with lower FMD. However, we found that a low triglyceride level was associated with low FMD among HD patients. Increased serum levels of triglycerides have been associated with endothelial dysfunction in several populations, including those with metabolic syndrome, chronic kidney disease and coronary artery disease [40-42]. Increasing evidence suggests that malnutrition and inflammation are common in HD patients [43], in whom a low triglyceride level is considered to be an indicator of malnutrition. Malnutrition, inflammation and atherosclerosis interact with inflammatory cytokines and tumor necrosis factor- $\alpha$, eventually leading to endothelial dysfunction [44]. Nevertheless, further studies are needed to confirm the association between triglyceride level and FMD among different populations.

Another interesting finding of this study is that high calcium-phosphate product was significantly associated with low FMD. Hyperphosphatemia can increase calcium-phosphate production through direct and indirect mechanisms [45], and both hyperphosphatemia and calcium-phosphate product have been shown to play a key role in vascular calcification in HD patients [46]. Stevens et al. reported that phosphate supplements were associated 
with a significant reduction in FMD among healthy volunteers [47]. A possible molecular mechanism is that hyperphosphatemia alters the vascular endothelial growth factor signaling pathway and increases p53 expression, leading to a reduction in total phosphate and endothelial NO synthase expression. Eventually, this reduction in NO results in endothelial dysfunction [47].

The last finding is that low HDL-cholesterol was associated with low SPP of plantar portions. HDL-cholesterol is a complex molecule with many potentially atheroprotective activities such as reverse cholesterol transport, inhibiting the expression of adhesion molecules on endothelial cells and stimulating endothelial NO synthase to promote vasodilation [48]. A possible explanation for our finding is that low HDL-cholesterol has been shown to decrease the activation of endothelial NO synthase, leading to impaired vasodilation [49]. Impaired restoration of vasodilation would then lead to a decrease in the SPP value.

There are several limitations to this study. First, only 80 patients were enrolled, so studies with a larger number of participants are needed to confirm our findings. The limited number of study patients severely reduced the power of the study. Second, as all of the study patients were enrolled from a single regional hospital in Taiwan, our findings may not be generalizable to other areas. Third, due to the cross-sectional study design, we were unable to evaluate causal relationships and long-term clinical outcomes. Fourth, the sensitivity of ABI and baPWV for detecting PAD in HD patients has been reported to be low [50]. Nonetheless, our results highlight the importance of FMD and SPP on PAD in HD patients.

In conclusion, we identified an association between SPP of the feet with ABI and baPWV. However, there was no correlation between FMD and ABI or baPWV in the HD patients in this study.

Author Contributions: Conceptualization, C.-H.W., Y.-H.W., Y.-C.L., C.-W.C., P.-Y.W., J.-C.H., Y.-C.T., S.-C.C., J.-M.C. and S.-J.H.; methodology, Y.-H.W., Y.-C.L., C.-W.C., P.-Y.W., J.-C.H., Y.-C.T., S.-C.C. and S.-J.H.; validation, S.-C.C.; formal analysis, C.-H.W. and S.-C.C.; investigation, C.-H.W., Y.-H.W., Y.C.L., C.-W.C., P.-Y.W., J.-C.H., Y.-C.T., S.-C.C., J.-M.C. and S.-J.H.; writing-original draft preparation, C.-H.W. and S.-C.C.; writing-review and editing, S.-C.C. and S.-J.H.; supervision, J.-M.C. and S.-J.H.; project administration, S.-C.C.; funding acquisition, S.-C.C. All authors have read and agreed to the published version of the manuscript.

Funding: This work was supported Kaohsiung Medical University Hospital (S-109020).

Institutional Review Board Statement: The study was conducted according to the guidelines of the Declaration of Helsinki, and ap-proved by the Institutional Review Board of Kaohsiung Medical University Chung-Ho Memorial Hospital (KMUHIRB-E(II)-20200315) and 2020/10/20 approval.

Informed Consent Statement: Informed consent was obtained from all subjects involved in the study.

Data Availability Statement: Data may be available upon request to interested researchers. Please send data requests to: Szu-Chia Chen, PhD, MD. Division of Nephrology, Department of Internal Medicine, Kaohsiung Medical University Hospital, Kaohsiung Medical University.

Acknowledgments: We thank WS FAR IR Medical Technology CO., LTD, who provided the machines for FMD and SPP measurement.

Conflicts of Interest: The authors declare no conflict of interest.

\section{References}

1. Six, I.; Flissi, N.; Lenglet, G.; Louvet, L.; Kamel, S.; Gallet, M.; Massy, Z.A.; Liabeuf, S. Uremic Toxins and Vascular Dysfunction. Toxins 2020, 12, 404. [CrossRef]

2. Nongnuch, A.; Kitiyakara, C.; Sappadungsuk, S.; Sathirapongsasuti, N.; Vipattawat, K.; Zhang, P.; Davies, N.; Davenport, A. Pilot study to investigate differences in middle molecules, oxidative stress and markers of peripheral vascular disease in patients treated by high flux haemodialysis and haemodiafiltration. PLoS ONE 2021, 16, e0258223. [CrossRef]

3. Garimella, P.S.; Hirsch, A.T. Peripheral artery disease and chronic kidney disease: Clinical synergy to improve outcomes. Adv. Chronic Kidney Dis. 2014, 21, 460-471. [CrossRef] [PubMed] 
4. Herzog, C.A.; Asinger, R.W.; Berger, A.K.; Charytan, D.M.; Diez, J.; Hart, R.G.; Eckardt, K.U.; Kasiske, B.L.; McCullough, P.A.; Passman, R.S.; et al. Cardiovascular disease in chronic kidney disease. A clinical update from Kidney Disease: Improving Global Outcomes (KDIGO). Kidney Int. 2011, 80, 572-586. [CrossRef] [PubMed]

5. Asceric, R.R.; Dimkovic, N.B.; Trajkovic, G.Z.; Ristic, B.S.; Jankovic, A.N.; Duric, P.S.; Ilijevski, N.S. Prevalence, clinical characteristics, and predictors of peripheral arterial disease in hemodialysis patients: A cross-sectional study. BMC Nephrol. 2019, $20,281$. [CrossRef] [PubMed]

6. Menke, A.; Muntner, P.; Wildman, R.P.; Dreisbach, A.W.; Raggi, P. Relation of borderline peripheral arterial disease to cardiovascular disease risk. Am. J. Cardiol. 2006, 98, 1226-1230. [CrossRef] [PubMed]

7. Raitakari, O.T.; Celermajer, D.S. Flow-mediated dilatation. Br. J. Clin. Pharmacol. 2000, 50, 397-404. [CrossRef]

8. Green, D.J.; Jones, H.; Thijssen, D.; Cable, N.T.; Atkinson, G. Flow-mediated dilation and cardiovascular event prediction: Does nitric oxide matter? Hypertension 2011, 57, 363-369. [CrossRef]

9. Higashi, H. Assessment of endothelial function. History, methodological aspects, and clinical perspectives. Int. Heart J. 2015, 56, 125-134. [CrossRef]

10. Jarrete, A.P.; Zanesco, A.; Delbin, M.A. Assessment of endothelial function by flow-mediated dilation in diabetic patients: Effects of physical exercise. Mot. Rev. Educ. Física 2016, 22, 3-11. [CrossRef]

11. Verbeke, F.H.; Pannier, B.; Guerin, A.P.; Boutouyrie, P.; Laurent, S.; London, G.M. Flow-mediated vasodilation in end-stage renal disease. Clin. J. Am. Soc. Nephrol. 2011, 6, 2009-2015. [CrossRef] [PubMed]

12. Chen, J.; Hamm, L.L.; Mohler, E.R.; Hudaihed, A.; Arora, R.; Chen, C.S.; Liu, Y.; Browne, G.; Mills, K.T.; Kleinpeter, M.A.; et al. Interrelationship of Multiple Endothelial Dysfunction Biomarkers with Chronic Kidney Disease. PLoS ONE 2015,10 , e0132047.

13. Pan, X.; Chen, G.; Wu, P.; Han, C.; Ho, J.K. Skin perfusion pressure as a predictor of ischemic wound healing potential. Biomed. Rep. 2018, 8, 330-334. [CrossRef] [PubMed]

14. Pitts, J. Skin Perfusion Pressure. J. Diagn. Med. Sonogr. 2014, 30, 213-216. [CrossRef]

15. Pan, X.; You, C.; Chen, G.; Shao, H.; Han, C.; Zhi, L. Skin perfusion pressure for the prediction of wound healing in critical limb ischemia: A meta-analysis. Arch. Med. Sci. 2018, 14, 481-487. [CrossRef]

16. Leskinen, Y.; Salenius, J.P.; Lehtimaki, T.; Huhtala, H.; Saha, H. The prevalence of peripheral arterial disease and medial arterial calcification in patients with chronic renal failure: Requirements for diagnostics. Am. J. Kidney Dis. 2002, 40, 472-479. [CrossRef] [PubMed]

17. Matsumae, T.; Abe, Y.; Murakami, G.; Ishihara, M.; Ueda, K.; Saito, T. Determinants of arterial wall stiffness and peripheral artery occlusive disease in nondiabetic hemodialysis patients. Hypertens. Res. 2007, 30, 377-385. [CrossRef]

18. Ono, K.; Tsuchida, A.; Kawai, H.; Matsuo, H.; Wakamatsu, R.; Maezawa, A.; Yano, S.; Kawada, T.; Nojima, Y. Ankle-brachial blood pressure index predicts all-cause and cardiovascular mortality in hemodialysis patients. J. Am. Soc. Nephrol. 2003, 14, 1591-1598. [CrossRef]

19. Corretti, M.C.; Anderson, T.J; Benjamin, E.J.; Celermajer, D.; Charbonneau, F.; Creager, M.A.; Deanfield, J.; Drexler, H.; Gerhard-Herman, M.; Herrington, D.; et al. Guidelines for the ultrasound assessment of endothelial-dependent flow-mediated vasodilation of the brachial artery: A report of the International Brachial Artery Reactivity Task Force. J. Am. Coll. Cardiol. 2002, 39, $257-265$. [CrossRef]

20. Hofstra, L.; Tordoir, J.H.; Kitslaar, P.J.; Hoeks, A.P.; Daemen, M.J. Enhanced cellular proliferation in intact stenotic lesions derived from human arteriovenous fistulas and peripheral bypass grafts. Does it correlate with flow parameters? Circulation 1996, 94, 1283-1290. [CrossRef]

21. Guo, X.; Li, J.; Pang, W.; Zhao, M.; Luo, Y.; Sun, Y.; Hu, D. Sensitivity and specificity of ankle-brachial index for detecting angiographic stenosis of peripheral arteries. Circ. J. 2008, 72, 605-610. [CrossRef]

22. Yamashina, A.; Tomiyama, H.; Takeda, K.; Tsuda, H.; Arai, T.; Hirose, K.; Koji, Y.; Hori, S.; Yamamoto, Y. Validity, reproducibility, and clinical significance of noninvasive brachial-ankle pulse wave velocity measurement. Hypertens. Res. 2002, 25, 359-364. [CrossRef]

23. Tomiyama, H.; Yamashina, A.; Arai, T.; Hirose, K.; Koji, Y.; Chikamori, T.; Hori, S.; Yamamoto, Y.; Doba, N.; Hinohara, S. Influences of age and gender on results of noninvasive brachial-ankle pulse wave velocity measurement-A survey of 12517 subjects. Atherosclerosis 2003, 166, 303-309. [CrossRef]

24. Yokoyama, H.; Shoji, T.; Kimoto, E.; Shinohara, K.; Tanaka, S.; Koyama, H.; Emoto, M.; Nishizawa, Y. Pulse wave velocity in lower-limb arteries among diabetic patients with peripheral arterial disease. J. Atheroscler. Thromb. 2003, 10, 253-258. [CrossRef] [PubMed]

25. Gupta, N.; Giri, S.; Rathi, V.; Ranga, G.S. Flow Mediated Dilatation, Carotid Intima Media Thickness, Ankle Brachial Pressure Index and Pulse Pressure in Young Male Post Myocardial Infarction Patients in India. J. Clin. Diagn. Res. 2016, 10, OC35-OC39. [CrossRef] [PubMed]

26. Vigna, G.B.; Satta, E.; Bernini, F.; Boarini, S.; Bosi, C.; Giusto, L.; Pinotti, E.; Tarugi, P.; Vanini, A.; Volpato, S.; et al. Flow-mediated dilation, carotid wall thickness and HDL function in subjects with hyperalphalipoproteinemia. Nutr. Metab. Cardiovasc. Dis. 2014, 24, 777-783. [CrossRef] [PubMed]

27. Kaczmarczyk, P.; Maga, P.; Nizankowski, R.; Januszek, R.; Frolow, M.; Maga, M.; Koscielniak, J.; Belowski, A. The relationship between pulse waveform analysis indices, endothelial function and clinical outcomes in patients with peripheral artery disease treated using percutaneous transluminal angioplasty during a one-year follow-up period. Cardiol. J. 2020, 27, 142-151. [CrossRef] 
28. Tomiyama, H.; Ishizu, T.; Kohro, T.; Matsumoto, C.; Higashi, Y.; Takase, B.; Suzuki, T.; Ueda, S.; Yamazaki, T.; Furumoto, T.; et al. Longitudinal association among endothelial function, arterial stiffness and subclinical organ damage in hypertension. Int. J. Cardiol. 2018, 253, 161-166. [CrossRef]

29. Nakamura, T.; Uematsu, M.; Horikoshi, T.; Yoshizaki, T.; Kobayashi, T.; Saito, Y.; Watanabe, Y.; Nakamura, K.; Obata, J.E.; Kugiyama, K. Improvement in Brachial Endothelial Vasomotor Function and Brachial-Ankle Pulse Wave Velocity Reduces the Residual Risk for Cardiovascular Events after Optimal Medical Treatment in Patients with Coronary Artery Disease. J. Atheroscler. Thromb. 2020, 28, 57562. [CrossRef]

30. Korkmaz, H.; Onalan, O. Evaluation of endothelial dysfunction: Flow-mediated dilation. Endothelium 2008, 15, 157-163. [CrossRef]

31. Laurent, S.; Cockcroft, J.; Van Bortel, L.; Boutouyrie, P.; Giannattasio, C.; Hayoz, D.; Pannier, B.; Vlachopoulos, C.; Wilkinson, I.; Struijker-Boudier, H.; et al. Expert consensus document on arterial stiffness: Methodological issues and clinical applications. Eur. Heart J. 2006, 27, 2588-2605. [CrossRef] [PubMed]

32. Stary, H.C. Natural history and histological classification of atherosclerotic lesions: An update. Arterioscler. Thromb. Vasc. Biol. 2000, 20, 1177-1178. [CrossRef] [PubMed]

33. Davis, M.; Rajagopalan, S. Is skin perfusion pressure a useful screening tool for peripheral arterial disease in patients on hemodialysis? Nat. Clin. Pract. Nephrol. 2007, 3, 598-599. [CrossRef] [PubMed]

34. Ishioka, K.; Ohtake, T.; Moriya, H.; Mochida, Y.; Oka, M.; Maesato, K.; Hidaka, S.; Kobayashi, S. High prevalence of peripheral arterial disease (PAD) in incident hemodialysis patients: Screening by ankle-brachial index (ABI) and skin perfusion pressure (SPP) measurement. Ren. Replace. Ther. 2018, 4, 1-7. [CrossRef]

35. Shimazaki, M.; Matsuki, T.; Yamauchi, K.; Iwata, M.; Takahashi, H.; Sakamoto, K.; Ohata, J.; Nakamura, Y. Measurement of Skin Perfusion Pressure in Hemodialyzed Patients: Association with Toe/Brachial Index. Dial. Transplant. 2008, 37, 431-438. [CrossRef]

36. Castronuovo Jr, J.J.; Adera, H.M.; Smiell, J.M.; Price, R.M. Skin perfusion pressure measurement is valuable in the diagnosis of critical limb ischemia. J. Vasc. Surg. 1997, 26, 629-637. [CrossRef]

37. Wu, J.; Liu, M.; Huang, H. Risk Factors Associated with Diabetic Foot Ulcers and Its Relationship with ABI and Brachial-Ankle Pulse Wave Velocity. Int. J. Low. Extrem. Wounds 2021, 1534734620982233. [CrossRef] [PubMed]

38. Samsamshariat, S.Z.A.; Sakhaei, F.; Salehizadeh, L.; Keshvari, M.; Asgary, S. Relationship between Resistin, Endothelin-1, and Flow-Mediated Dilation in Patient with and without Metabolic Syndrome. Adv. Biomed. Res. 2019, 8, 16.

39. Fukumoto, K.; Takemoto, Y.; Yoshikawa, J.; Norioka, N.; Iguchi, T.; Namikawa, H.; Tochino, Y.; Yoshiyama, M.; Shuto, T. Predictors of endothelial function improvement in patients with mild hypertriglyceridemia without evidence of coronary artery disease treated with purified eicosapentaenoic acid. Atherosclerosis 2020, 309, 27-32. [CrossRef]

40. Nakamura, T.; Takano, H.; Umetani, K.; Kawabata, K.; Obata, J.E.; Kitta, Y.; Kodama, Y.; Mende, A.; Ichigi, Y.; Fujioka, D.; et al. Remnant lipoproteinemia is a risk factor for endothelial vasomotor dysfunction and coronary artery disease in metabolic syndrome. Atherosclerosis 2005, 181, 321-327. [CrossRef]

41. Sonmez, A.; Yilmaz, M.I.; Saglam, M.; Unal, H.U.; Gok, M.; Cetinkaya, H.; Karaman, M.; Haymana, C.; Eyileten, T.; Oguz, Y.; et al. The role of plasma triglyceride/high-density lipoprotein cholesterol ratio to predict cardiovascular outcomes in chronic kidney disease. Lipids Health Dis. 2015, 14, 29. [CrossRef] [PubMed]

42. Yunoki, K.; Nakamura, K.; Miyoshi, T.; Enko, K.; Kubo, M.; Murakami, M.; Hata, Y.; Kohno, K.; Morita, H.; Kusano, K.F.; et al. Impact of hypertriglyceridemia on endothelial dysfunction during statin + / - ezetimibe therapy in patients with coronary heart disease. Am. J. Cardiol. 2011, 108, 333-339. [CrossRef] [PubMed]

43. Stenvinkel, P. Inflammatory and atherosclerotic interactions in the depleted uremic patient. Blood Purifier 2001, $19,53-61$. [CrossRef] [PubMed]

44. Zyga, S.; Christopoulou, G.; Malliarou, M. Malnutrition-inflammation-atherosclerosis syndrome in patients with end-stage renal disease. J. Ren. Care 2011, 37, 12-15. [CrossRef]

45. Cozzolino, M.; Dusso, S.A.; Slatopolsky, E. Role of Calcium-Phosphate Product and Bone-Associated Proteins on Vascular Calcification in Renal Failure. J. Am. Soc. Nephrol. 2001, 12, 2511-2516. [CrossRef] [PubMed]

46. Block, G.A.; Hulbert-Shearon, T.E.; Levin, N.W.; Port, F.K. Association of serum phosphorus and calcium x phosphate product with mortality risk in chronic hemodialysis patients: A national study. Am. J. Kidney Dis. 1998, 31, 607-617. [CrossRef]

47. Stevens, K.K.; Denby, L.; Patel, R.K.; Mark, P.B.; Kettlewell, S.; Smith, G.L.; Clancy, M.J.; Delles, C.; Jardine, A.G. Deleterious effects of phosphate on vascular and endothelial function via disruption to the nitric oxide pathway. Nephrol. Dial. Transplant. 2017, 32, 1617-1627. [CrossRef]

48. Kopecky, C.; Genser, B.; Drechsler, C.; Krane, V.; Kaltenecker, C.C.; Hengstschlager, M.; Marz, W.; Wanner, C.; Saemann, M.D.; Weichhart, T. Quantification of HDL proteins, cardiac events, and mortality in patients with type 2 diabetes on hemodialysis. Clin. J. Am. Soc. Nephrol. 2015, 10, 224-231. [CrossRef]

49. Mineo, C.; Deguchi, H.; Griffin, J.H.; Shaul, P.W. Endothelial and antithrombotic actions of HDL. Circ. Res. 2006, 98, 1352-1364. [CrossRef]

50. Okamoto, K.; Oka, M.; Maesato, K.; Ikee, R.; Mano, T.; Moriya, H.; Ohtake, T.; Kobayashi, S. Peripheral arterial occlusive disease is more prevalent in patients with hemodialysis: Comparison with the findings of multidetector-row computed tomography. Am. J. Kidney Dis. 2006, 48, 269-276. [CrossRef] 